\title{
PROLOGUE
}

\section{Thinking from the Desert}

FOR THE GREATER PART OF MY LIFE I have made my home in the Southwestern desert, a region with a special character perhaps incomprehensible to those who have never come under its awesome influence. The magnificence of the desert is impossible to describe, but it resides at least in part in the fact that it is at once a place of vast extremes and a place indifferent to extremes. The withering stillness of an August day threatens anyone unprotected from the sun; but the winds of March and April can as easily make the sand itself into a near lethal weapon. At times the desert presents itself as a desiccated emptiness, offering not a drop of water to sustain life; without warning, however, torrential rains can create dangerous floods, after which the desert blossoms with an inconceivable variety of living things. There are no half-measures here. And yet the contrasting expressions of the desert are played against a background of brooding, almost alien, constancy that renders them rhythmic and harmonious in some vaguely reassuring fashion.

When I first came to this area nearly twenty-five years ago, our culture was living under the threat of a mushroomshaped cloud born from out of these very desert spaces. What irony, once having secured ourselves somewhat from the threat of Atomic disaster, that we should have turned our 
paranoid fears toward the "other mushroom," itself a product of the same desert environment. Here in the desert the two antithetical symbols meet: the psychedelic plant and the nuclear flower of evil. I reached maturity during that brief period in which our culture dangled between these two extremes, awaiting the judgment of history.

But such extremes have a way of being rendered less severe, not through adjustment or compromise, but simply by virtue of the vastness of the alternative possibilities that provide their background. The desert can well symbolize that vastness which is the primary occasion for hope in the face of the restricting dystopias that have iegun to pattern our intellectual landscape.

As a symbol of the situation within which we find ourselves, the desert can also serve as a source of renewal. This may be so because the desert is, above all else, a place of solitariness; and it is only from solitude that renewal can come. We wonder as we wander, and only as we wander. In the mountains one struggles for the peak; in the forest each tall tree can become a familiar landmark indicating the proper way. But the desert shifts and changes, defying attempts to explore it, to chart it, or to tame it. The desert is a place for wandering. And in the absence of firm values and clear goals we need less to follow stoically well-worn paths and more to practice the art of wandering, which can occur only if we retreat into deserted regions of life or mind. The desert is both symbol and source of our attempts to renew the activity of wondering, which can give birth to a new sensibility. Thus, it should not be at all surprising that the initial stimulus for a culture's activities is to be found in its religious experiences, since religions arise, metaphorically (and often quite literally), from out of the desert.

The wasteland imagery employed by so many of our recent cultural prophets has perhaps misled us. There is a vast difference between a wasteland and desert. Ours is not so much a land laid waste, which, once cleared of its rubble, can be rebuilt through human effort. Doubtless, when the rains come they will rust and rot the artifacts of our tired civilization, but it would be a mistake to believe that we ought to use 
our energies to renovate the collapsing structures of our traditional culture. It is time to look beyond, to the promises of the desert. For when the rains touch the desert, myriad blossoms shall spring forth.

Perhaps the hardest lesson we must learn is that we are not rainmakers. Neither the passing away of the old nor the birth of the new is within our powers to determine. We are desert dwellers, and thus depend upon the grace or the judgment of our ambience. Our cultural desert is rife with possibilities, and only when some from among these potentialities begin to emerge in more articulate form can any of us feel capable of efficacious action on behalf of a novel future.

In the attempt to write a philosophy of culture I have had continual recourse to such reflections as these, for it is clearat least to me-that the endeavor to promote cultural selfunderstanding cannot result in a coherent vision unless that vision is derived from a sympathetic consideration of what may appear to be contrasting, and at times conflicting, modalities of thought. And it is equally clear that we must avoid what I shall later discuss under the rubric of the Pelagian Fallacythat is, the argument from freedom in principle to freedom in fact. Our public world is at present a sphere of determination upon which we depend until such time as articulate possibilities for future attainment are manifest. This assumption concerning the lack of freedom in public activity will receive sufficient explication in the course of the essays that follow, but I must say more here concerning the contrasting modes of thought upon which I have drawn in my endeavor to describe our cultural condition.

My greatest hesitation concerning the speculations on our cultural situation that follow this brief apologia is with regard to the unbalanced relationship between the principles and the metaphors that constitute the foundation and superstructure of this work. "Principles," the beginning points of thought and action, are valid only to the extent that they permit themselves to be disciplined by "metaphors," the means of evoking sensibility beyond sense. And metaphors are efficacious only to the extent that they have a "beginning"-i.e., are principled. A principle is not a beginning in itself, but the 
beginning of something in particular. The answer to the question "The beginning of what?" requires at some point along the line the resort to a metaphor. And a metaphor is not an end in itself, but the end of a beginning - the means to a beyond, but to a particular beyond.

The struggle between metaphors as symbols of thought and principles as sources of thought, the special character of which Plato articulated near the beginning of our present epoch, seems to be peculiarly intense today. Neither our poets nor our philosophers seem able to supply us with that kind of sustenance that would allow us to meet our situation with fortitude. Poets, shepherds of the metaphors that incite, evoke, and reprove us, and philosophers, caretakers of the principles that situate, articulate, and organize our sensibilities, have quarreled throughout history. That it is, after all, a family quarrel, one that advertises the essential interdependence of the conflicting parties, has not made the discord any easier to resolve.

The philosopher of culture-unlike his more analytic and systematic colleagues-is condemned to (and often condemned by) the tensions and conflicts of his ambience. Thus, in addition to the many failings attributable solely to its author, this work reflects the mixed metaphorical imagery required to elicit the confusion that, willy nilly, characterizes our present situation. This means that the metaphorical structure is at times splayed and unfocused. On the other hand, the account of contemporary culture I have given skirts on the edges of inconsistency since it is involved in assessing essentially incompatible, and sometimes contradictory, principles, not so much to highlight their contradictions (though at times that will be the purpose) as to articulate their distinctive explanatory powers.

In articulating cultural importances it is necessary to take an extremely abstract and general perspective since what is discernibly important is widespread, pervasive, and characteristically blunt. As a consequence of the abstractive level at which I have operated I have often resorted to typological devices of a very general sort as a means of describing these pervasive cultural determinants. It is not my purpose to claim 
validity for such devices at any but the level of cultural selfunderstanding. I do insist, however, that this resort to typology and blunt characterization is essential to the task at hand. The phenomenon of culture per se has about it a quality of massiveness, which means that it is distorted if over-refined. It is precisely the penchant of most contemporary philosophers for analytic refinement rather than speculative synthesis that has led to the pernicious neglect of philosophy of culture so evident in our period.

Part of the difficulty I am recounting is grounded, of course, in the very nature of speculative philosophy of culture, which must involve that kind of reflection that consists in holding a mirror, a speculum, before the object of one's investigation and noting the variety and sinuosities of the captured images. One cannot, in so doing, attempt to overclarify the reflections. It is useless to try to clean one's dirty face by polishing the mirror; the cleaner the mirror, the more clearly we see the soiled countenance. It took the special genius of Charles Sanders Peirce to recognize the existence of "the objective vague," that which could be clarified and articulated only at the risk of falsification.

Our cultural situation is objectively vague. The speculations that follow share in that vagueness by presenting a reflection of the form, the substance, and the shadows of our contemporary cultural experience. In order to present such a reflection it is necessary to make use of both metaphors and principles in ways that promote a sense of the vagueness and uncertainty of our situation. Before one is tempted to attribute the apparent stylistic inelegancies merely to unvetted prose, I do hope he or she will consider the special character of the communicative task that the author has set for himself, and the way that task has shaped the style and substance of this work. A recent faddish slogan to the contrary notwithstanding, in the speculations that follow the medium is precisely not the message.

Closely associated with the tension between the principles and the metaphors discussed above, and partly responsible for it, is what can only be termed the "aesthetic incompatibility" of the arguments and the conclusions of this 
work. This incompatibility results from the fact that many of the conclusions that may be plausibly drawn concerning the direction of our technological future are bizarre in the extreme. And I have not hesitated to draw them. On the other hand, the arguments leading up to, or defending, these conclusions are gathered from the broadest possible of cultural resources and are couched for the most part in traditional philosophic language. This has led to a disquieting feeling on my part that, while the professional philosophers who read this book are apt to appreciate its arguments, they may find the conclusions drawn from these arguments to be unacceptable except as utopian fantasies; and while the wider public will be quite interested in some of the conclusions concerning our technological future, they may not feel disposed to wade through the philosophic arguments-especially when they can get even more sensational speculations written in a much less demanding style.

But surely any such suspicion underestimates both philosopher and non-philosopher alike. For most contemporary philosophers have been forced to learn the lesson best expressed by Miguel de Unamuno: "The fact that the consequences of a proposition are catastrophic says nothing against the truth of the proposition." Nor should we believe that the non-philosopher is unsympathetic with Cervantes' insight, "The road is better than the inn." The first lesson teaches us to accept the consequences of our arguments no matter how bizarre they might at first appear. The second lesson shows us that arguments are not for the sake of their conclusions, since it is in the arguments themselves that we discover the flow of experience and the rhythms of life that ground all philosophic inquiry. "Conclusions" are mere stopping-off places that punctuate a journey without ultimate destination. We argue, we speculate, we reflect, because the road is better than the inn; we conclude our arguments only as a means of pausing for refreshment along the way.

There is yet another tension present in this work. It is that between the traditions of the so-called Western, or AngloEuropean philosophy, on the one hand, and the thinking indigenous to classical Oriental-particularly Chinese-cul- 
ture, on the other. This work is a sequel to my The Civilization of Experience, 1 a speculative construction of a theory of culture employing the conceptualization of Alfred North Whitehead, our century's foremost philosopher of process. Those familiar with that work may believe that I have here traveled too far in the direction of exotic philosophic sensibilities in my effort to demonstrate the relevance of the traditions of process philosophy for an understanding of contemporary culture. Comparative philosophy is relatively new, and we have yet to develop criteria with which to assess the feasibility of importing alien sensibilities into contexts that are prima facie incompatible with them. In defense of my use of Oriental philosophies, I can only say that those who are willing to reflect with me on the issues considered in this work should come to appreciate both the relevance of process thought for the articulation of our cultural ambience, as well as the manner in which certain Oriental concepts and doctrines clarify and render more effective the process perspective.

Finally, I should say something of a tension that is not explicitly present in this work, but one that, doubtless, many will think ought to be: I refer to the tension between my expressed views and those over against which my vision stands. Speculative philosophy of culture, as I conceive it, must refuse the gambits offered by both absolutist and relativist understandings. I have not been blind to the scandalous relativism that emerges from a broad assessment of cultural evidences. But I have not sought to resolve the dilemma associated with philosophical relativity by recourse to the traditional method of dialectical refutation. In ages of uncertainty philosophic thinking progresses, haltingly, through the gradual enlargement of understanding; attempts to reduce the intellectual anxieties attendant upon the variety of conflicting truthclaims through an overly confident employment of dialectics can serve us no better than does the skeptical accession to the Protagorean Principle. My arguments are, for the most part, to be construed as seeking neither to establish truths nor to claim that no such establishment is possible. The burden of the speculative philosopher is to present a vision of sufficient coherence, complexity, and generality that it may serve as a 
context within which more specialized assertions of the skeptics and constructive dialecticians may find meaningful engagement.

Given the apologetic context within which most philosophic endeavors proceed, this book must be counted somewhat eccentric, and not a little strange. I confess I am worried less by the likelihood that the work will not be sympathetically received and more by the possibility that the book is not sufficiently strange to match the strangeness of the times. I find myself hoping that some among the readers of this work, less fastidious than I, will be stimulated to speculations far beyond those I have provided. For I cannot escape the belief that any vision of the future that leads us beyond mere stagnation, or the decline into infrahuman existence, must be radical in the extreme. Having said this, however, I must insist that I hold no illusions about the nature and efficacy of philosophic speculation. Mine is not a clarion call. It is, rather, a celebration of the uncertainty of the future as a means of stirring the ashes of the old world, and of endeavoring to anticipate the form of the Phoenix and the direction of her flight.

NOTE

1. (New York: Fordham University Press, 1973). 


\section{THE}

UNCERTAIN

PHOENIX 
